\title{
BALANÇOS, VISADAS CRÍTICAS
}

A edição número 65 encerra o ano de publicações da Revista do Instituto de Estudos Brasileiros. Aproveitando a ocasião, realizamos um balanço sumário para indicar algumas questões que operam no dia a dia de um periódico científico. Em 20I6, lançamos três números - além das seções fixas, a revista estampou 35 artigos (II, no n 63, I4, no n. 64, e Io, no n. 65). Desses, pelo menos 60\% foram assinados por autores que não pertencem à Universidade de São Paulo, e uma boa parte trabalha em instituições fora do estado de São Paulo. Essa proporção diz respeito a um acordo elaborado pela Scientific Electronic Library Online - SciELO (a biblioteca eletrônica que publica nossa revista), que visa prevenir o comprometimento da qualidade dos artigos, o qual pode, eventualmente, ser produzido pela endogenia, que é, em algumas situações, uma perturbação na dinâmica acadêmica. Isso não quer dizer que os $40 \%$ restantes estejam contaminados por procedimentos de seleção indevidos, pois outro anteparo para garantir escolhas criteriosas, representado pelo recurso a pareceristas gabaritados, assegura de forma consistente a qualidade dos artigos mais do que a própria lógica de distribuição geográfica e institucional antiendogenia. Situa-se aqui um ponto importante para alargar a discussão sobre a qualidade e a natureza de nossas revistas científicas.

A obediência ao critério proporcional 60\%/40\% é algo que os editores constroem no momento da edição final do número; não há como (e nem seria cabível) criar um filtro que recepcionasse os artigos considerando essa proporção. No fluxo de submissão de artigos da RIEB, costumam chegar mais contribuições do estado de São Paulo e da Universidade de São Paulo. Onde está o ponto que transforma esse fato em questão difícil de operar? Vige ao mesmo tempo um outro aspecto do acordo orientador das revistas científicas, que se refere a um tempo-limite de publicação dos artigos aprovados. Ora, se os artigos que são aprovados em maior número têm menos espaço para publicação, é razoável que eles aguardem mais tempo para publicação. É importante que se compreenda isso, que nossos colaboradores tenham consciência disso, assim como os avaliadores da RIEB e das revistas científicas em geral. Regras podem fazer sentido a princípio, mas elas precisam ser chanceladas pela experiência, pois correm o risco de se tornarem irracionais.

Com a nossa proposta de discussão mais ampla sobre o espectro quantitativo na montagem de uma revista científica, apresentamos este número, que traz o complemento do Dossiê do projeto interdisciplinar "Dinâmicas de urbanização e representações 
espaciais: abordagem geo-histórica dos territórios com Sistemas de Informação Geográfica (SIG)", na parceria entre a Université Jean Moulin (Lyon 3), da França, e algumas unidades da Universidade de São Paulo, entre elas o IEB (vide apresentação interna do Dossiê), no convênio USP/Cofecub. Somando as duas partes (a primeira foi publicada da RIEB n. 64), foram I4 artigos de pesquisadores brasileiros e franceses. Reputamos o formato Dossiê como uma importante modalidade de expressão para os artigos científicos, pois nesses casos, além do que cada artigo pode significar e repercutir individualmente, ele se beneficia com outras camadas de significação geradas na trama do conjunto de artigos, que pode ser ao mesmo tempo complementar, assim como produtora de contrapontos estimulantes.

Outros três artigos coligidos neste número, nas áreas da educação, da história econômica e dos estudos literários, reafirmam o caráter multidisciplinar da RIEB. Os dois primeiros abordam, respectivamente, temas de grande atualidade: a questão racial e o problema da desigualdade social na experiência brasileira. "A educação para as relações étnico-raciais e os estudos sobre racismo no Brasil”, assinado pelo professor Roberto da Silva e pelo mestre em Educação Juliano da Silva Tobias, discute, em perspectiva histórica, no século XX, teorias raciais, desembocando na discussão sobre o sistema de cotas e as ações afirmativas em nosso país. "O Bolsa Família e a tradução regional da questão social”, artigo do professor Tadeu Alencar Arrais, coloca em pauta o lugar do Estado "na condução das políticas sociais", avaliando situação e resultados do Programa Bolsa Família, criado em 2003. A professora Maria Regina Barcelos Bettiol, no artigo "Mário de Andrade e o gênero epistolar: o esboço de uma teoria”, explora um dos muitos ângulos de interesse da vultosa correspondência do criador de Macunaíma.

A seção Documentação, em sintonia com o Dossiê, traz em primeira mão carta de Antonietta Penteado da Silva Prado, documento conservado no Fundo Caio Prado Júnior, no patrimônio do IEB-USP. Dona Antonietta é a mãe de Caio Prado Júnior. E na carta citada comenta um evento importante na história da cidade de São Paulo, que foi a inauguração do Theatro Municipal. Esse comentário, muito interessante, abre a possibilidade para uma interpretação provocativa, feita pelo professor Jaime Tadeu Oliva, sobre a atmosfera polêmica que reinava na época sobre os destinos urbanos da cidade.

Duas resenhas também integram este número, focalizando obras que colocam em circulação importantes documentos de fonte primária da história nacional, cobrindo do século XVI ao XIX. A professora Regina Zilberman avalia a publicação, em letra tipográfica, dos alentados volumes do Livro do Tombo do Mosteiro de São Bento da Bahia, promovida pela equipe capitaneada por dom Gregório Paixão, OSB, e pelas professoras Célia Marques Telles e Alicia Duhá Lose. O mestrando do IEB/USP Marcelo Maraninchi se debruça sobre a edição crítica do Diário da minha viagem para Filadélfia, do jornalista Hipólito José da Costa, preparada pela pesquisadora Tânia Dias, da Fundação Casa de Rui Barbosa, do Rio de Janeiro.

Na produção da revista - um procedimento de equipe -, a Comissão Editorial contou com o exemplar profissionalismo do quadro técnico, administrativo e de estagiários da Divisão Científico-Cultural do IEB. O agradecimento estende-se aos 
professores Eliane Kuvasney, Jaime Tadeu Oliva e Ana Paula Cavalcanti Simioni; ao Setor de Arquivos do IEB, destacando a atuação de Elisabete Marin Ribas e de sua prestativa equipe no trabalho de pesquisa iconográfica e documental. Agradecemos ainda a André do Nascimento Serradas, da Divisão de Gestão de Sistemas de Comunicação e Disseminação de Produtos/Serviços do Sistema Integrado de Bibliotecas - SIBiUSP, de quem os editores em muitos momentos puderam se valer, contando com seus amplos e sólidos conhecimentos na área.

O editorial, os artigos, a seção documentação, as resenhas e o noticiário aqui reunidos ambicionam repercutir amplamente, instituindo profícuos diálogos críticos com nossos leitores. Boa leitura!

Marcos Antonio de Moraes, Jaime Tadeu Oliva, Stelio Marras Editores $^{\mathrm{I}}$

DOI: http://dx.doi.org/Io.II6o6/issn.23I6-90IX.voi65pI3-I5

I Docentes e pesquisadores do Instituto de Estudos Brasileiros - USP. 